\title{
Effects of 12-Week Supplementation of a Polyherbal Formulation in Old Adults with Prehypertension/Hypertension: A Randomized, Double-Blind, Placebo-Controlled Trial
}

\author{
Tian Shen $\mathbb{D}^{1},{ }^{1}$ Guoqiang Xing $\mathbb{D}^{2,3}$ Jingfen Zhu $\mathbb{D}^{1},{ }^{1}$ Yong Cai $\mathbb{D},{ }^{1}$ Shuxian Zhang, \\ Gang Xu, ${ }^{1}$ Yi Feng, ${ }^{1}$ Donghua $\mathrm{Li}^{4},{ }^{4}$ Jianyu Rao, ${ }^{5}$ and Rong Shi $\mathbb{1}^{6}$ \\ ${ }^{1}$ School of Public Health, Shanghai Jiao Tong University, Shanghai 200025, China \\ ${ }^{2}$ The Affiliated Hospital and the Second Clinical Medical College of North Sichuan Medical College, Nanchong Central Hospital, \\ Nanchong 637000, China \\ ${ }^{3}$ Lotus Biotech.com LLC, John Hopkins University-MCC, 9601 Medical Center Drive, Rockville, MD 20850, USA \\ ${ }^{4}$ Tang Qiao Community Health Service Center, Pudong New District, Shanghai 200127, China \\ ${ }^{5}$ Department of Pathology and Laboratory Medicine, David Geffen School of Medicine, University of California, \\ Los Angeles, CA 90095, USA \\ ${ }^{6}$ School of Public Health, Shanghai University of Traditional Chinese Medicine, Shanghai 201203, China
}

Correspondence should be addressed to Guoqiang Xing; gxing99@yahoo.com and Yong Cai; caiyong202028@163.com

Received 6 March 2019; Accepted 24 June 2019; Published 14 July 2019

Academic Editor: Jairo Kennup Bastos

Copyright (C) 2019 Tian Shen et al. This is an open access article distributed under the Creative Commons Attribution License, which permits unrestricted use, distribution, and reproduction in any medium, provided the original work is properly cited.

\begin{abstract}
Background. Uncontrolled blood pressure is the leading cause of mortality and disability due to associated cerebral and cardiovascular diseases and kidney failure. More than one-third of the old adult population have hypertension or prehypertension and many of their blood pressure are poorly controlled. Objective. We hypothesized that plant extracts-based antioxidants may benefit those with prehypertension/hypertension. Method. One hundred age- and gender-matched healthy older adults were randomly assigned to receive HyperBalance capsules $(n=50)$ or placebo $(n=50)$ at Tang-Qiao Community Health Service Center, Shanghai. Blood pressure and severity scores of hypertension treatment-related symptoms (dizziness, headache, ringing/buzzing in ears, rapid heart rate, and chest tightness) were evaluated before and after the 12-week intervention. Results. Ninety-eight people completed the study, with 2 dropouts in the placebo group before the end of the study. Forty-one subjects ( $82 \%$ ) of the HyperBalance group and 40 subjects (83.3\%) of the placebo group had prehypertension (systolic blood pressures (SBP) between 130-139 and diastolic blood pressure (DBP) between $85-89 \mathrm{mmHg}$ ), and 9 subjects (18\%) in the HyperBalance group and 8 subjects (16.7\%) in the placebo group had hypertension $(\geq 140 / 90 \mathrm{mmHg})$ before the intervention. HyperBalance significantly $(\mathrm{P}<0.01)$ reduced SBP from $136.18 \pm 4.38$ to $124.14 \pm 3.96 \mathrm{mmHg}$ and reduced DBP from $82.45 \pm 2.91$ to $80.24 \pm 2.41 \mathrm{mmHg}$, respectively, and reversed all 9 hypertension people to normotension or prehypertension state, whereas the placebo moderately reduced SBP from $135.79 \pm 4.22$ to $132.35 \pm 4.656 \mathrm{mmHg}$ and reduced DBP from $82.90 \pm 3.07$ to $82.27 \pm 3.01 \mathrm{mmHg}$. All symptom severity scores became significantly lower in the HyperBalance group than in the placebo group after HyperBalance intervention: dizziness $(0.82 \pm 0.44$; vs $2.02 \pm 0.64$, $\mathrm{P}<0.01)$; headache $(0.46 \pm 0.50$; vs $1.81 \pm 0.61, \mathrm{P}<0.01)$; ringing/buzzing in ears $(0.44 \pm 0.50$; vs $1.04 \pm 0.29, \mathrm{P}<0.01)$; and rapid heart rate and chest tightness $(0.30 \pm 0.46$; vs $0.92 \pm 0.28, \mathrm{P}<0.01)$. Conclusion. Polyherbal supplementation such as HyperBalance could benefit old adults with prehypertension/hypertension and improve treatment-related symptoms. Further studies are needed to validate the current findings.
\end{abstract}

\section{Introduction}

Uncontrolled high blood pressure is a leading cause of mortality and disability due to cardiovascular disease (CVD) and kidney failure [1]. For example, one in three adults in the US and China have high blood pressure, many of whom remain untreated [2-4]. A recent study in China shows the prevalence of CVD to be $36.0 \%$ for prehypertension 
(high-normal blood pressure) and 30.8\% for hypertension, respectively, both of which are correlated with age, gender, alcohol drinking, body mass index (BMI), abdominal obesity, and dyslipidemia $[2,5]$.

Individuals with prehypertension are characterized with either elevated systolic blood pressure (SBP) ranging from 120 to $139 \mathrm{mmHg}$ or a diastolic blood pressure (DBP) from 80 to $89 \mathrm{mmHg}$ and are at a higher risk of developing hypertension (high blood pressure, with the SBP/DBP readings $\geq 140 / 90 \mathrm{mmHg}$ ) compared to people with normal blood pressure. Individuals with prehypertension and hypertension, although often asymptomatic (without symptoms), can develop treatment-related symptoms such as dizziness, headaches, visual changes, fatigue, or other nonspecific symptoms after current medical treatment.

Individuals with prehypertension can significantly increase the risk for cardiovascular disorders and kidney problems [6]. It has been reported that a person with prehypertension is 3 times more likely to have a heart attack and 1.7 times more likely to have heart disease than a person with normal blood pressure [7]. Others show that prehypertension is associated with a risk-factor-adjusted hazard ratio for cardiovascular diseases of 2.5 in women and 1.6 in men [8].

Aging, obesity, high salt intake, lack of exercise, stress, depression, and insulin resistance all can contribute to prehypertension/hypertension $[2,9,10]$. More than half of individuals with high blood pressure have a salt-sensitive type of hypertension and progressive renal damage [11, 12]. Low birth weight, maternal smoking, and lack of breast feeding may be risk factors for adult essential hypertension [13].

Recent studies indicate that increased free radical production and diminished activities of antioxidant and nitric oxide (NO) are involved in the development of hypertension $[14,15]$. Low-density lipoprotein- (LDL-) cholesterol-induced $\mathrm{H}_{2} \mathrm{O}_{2}$ production is a major causative factor in endothelial perturbation and in the pathogenesis of atherosclerosis. Increased NADPH oxidase activity is also a major source of reactive oxygen species (ROS) in endothelial cells [16, 17]. Similarly, the stroke-prone spontaneously hypertensive rats (SHRSP) exhibit increased salt sensitivity and vascular release of superoxide but decreased total plasma antioxidant capacity [18]. The superoxide release in the SHRSP rats diminishes NO levels that can be reversed or restored by superoxide dismutase (SOD) administration. Thus, increased superoxide generation, decreased antioxidant capacity, elevated vascular inflammatory damage, and renal damage are involved in the progress of prehypertension to hypertension in human and experimental models of salt-sensitive blood pressure [18].

Prevention is considered the best strategy to lower the risk of prehypertension progressing to hypertension. Modification of lifestyle, including low-sodium, high-potassium diet, increasing physical activity, quitting smoking, reducing alcohol consumption, and maintaining a healthy weight, has been recommended $[19,20]$.

Alternatively, botanical herbs that have historically been used as an essential diet supplement could be potential agents for the management of prehypertension and hypertension [21-23].
For example, Gastrodia elata (EG) is one of the most common antihypertension ingredients prescribed by TCM doctors for hypertension [24]. EG contains gastrodin, gastrodigenin, gastrol, 4-Hydroxybenzaldehyde, and 2,4-Bis(4hydroxybenzyl) phenol as the main active components (Table 1). A recent randomized controlled trial showed that daily intravenous injection of 1,000mg gastrodin for 4 weeks significantly decreased systolic and diastolic blood pressures and reduced plasma endothelin (ET) levels but increased nitric oxide (NO) level in older adults with refractory hypertension who had higher plasma ET and lower level of NO than people with essential hypertension before the treatment [25]. Gastrodin also reduced blood pressure and inhibited angiotensin II (Ang II) and aldosterone (ALD) and the expression of angiotensin type 1 receptor (AT1R) but unregulated peroxisome proliferate-activated receptor gamma (PPAR $\gamma)$ in myocardium of spontaneously hypertensive rats (SHRs) [26]. EG also ameliorated high fructoseinduced dyslipidemia, hypertension, and endothelial dysfunction by downregulation of ET and adhesion molecules in the aorta [27]. Moreover, EG significantly restored the impaired vasorelaxation to acetylcholine and the reduced levels of endothelial nitric oxide synthase (eNOS) expression $[28,29]$. EG has anti-inflammatory and antiangiogenic activities, through inhibiting LPS-induced expression of inducible nitric oxide synthase (iNOS) and cyclooxygenase-2 [30-32].

Coadministration of multiple medicinal herbal ingredients is a common practice in traditional Chinese medicine. Such practice is to potentiate the bioavailability, activity, and efficacy of the key therapeutic ingredients, and to minimize or antagonize potential toxicities associated with the ingredients.

The primary goal of this exploratory, randomized, placebo-controlled observational study was to determine if administration of polyherbal supplement is beneficial to older adults who have high blood pressure and treatmentrelated symptoms.

\section{Methods}

The experimental design and procedures of this study were similar to what we recently reported $[24,33,34]$.

2.1. Samples Size Calculation and Participants Recruitment. This was a randomized, double-blind, placebo-controlled study. Sample size calculation was obtained by the calculation of the estimated experimental study parameters. SBP was chosen as the main outcome, assuming a baseline SBP at about about $135 \mathrm{~mm} \mathrm{Hg}$, and the standard deviation at about $7 \mathrm{~mm} \mathrm{Hg}$. It was expected that SBP would drop to $130 \mathrm{~mm} \mathrm{Hg}$ after the intervention:

$$
N=\frac{2\left(Z_{\alpha}+Z_{\beta}\right)^{2} \sigma^{2}}{d^{2}}
$$

$\sigma$ is the estimated SD; $\mathrm{d}$ is the difference between two groups of continuous variables mean.

According to the two-sided test, $\alpha=0.05 \beta=0.1, Z_{\alpha}=$ $1.96 Z_{\beta}=1.282$, the calculated sample size $\mathrm{N}$ is 41 . Assuming 


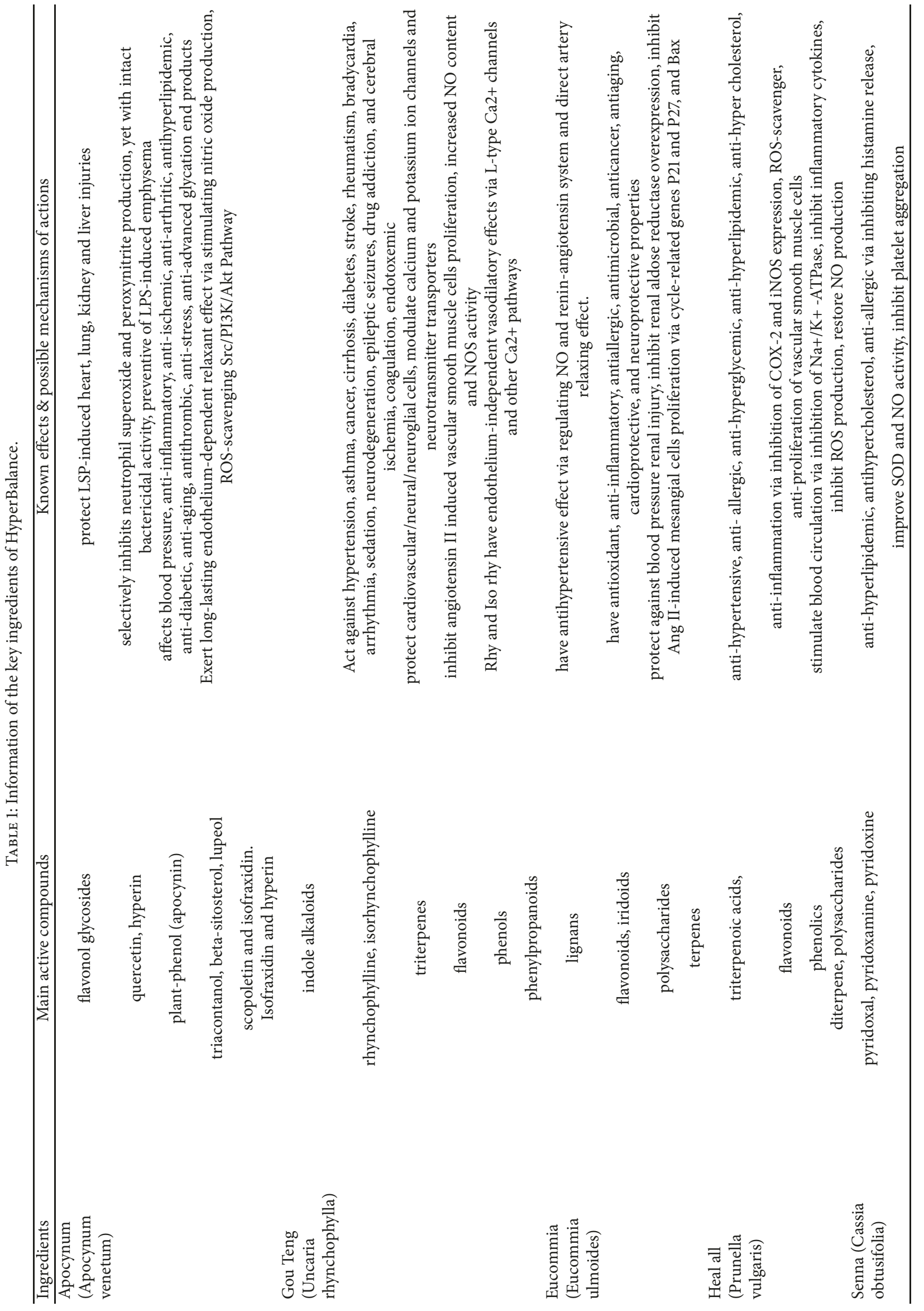




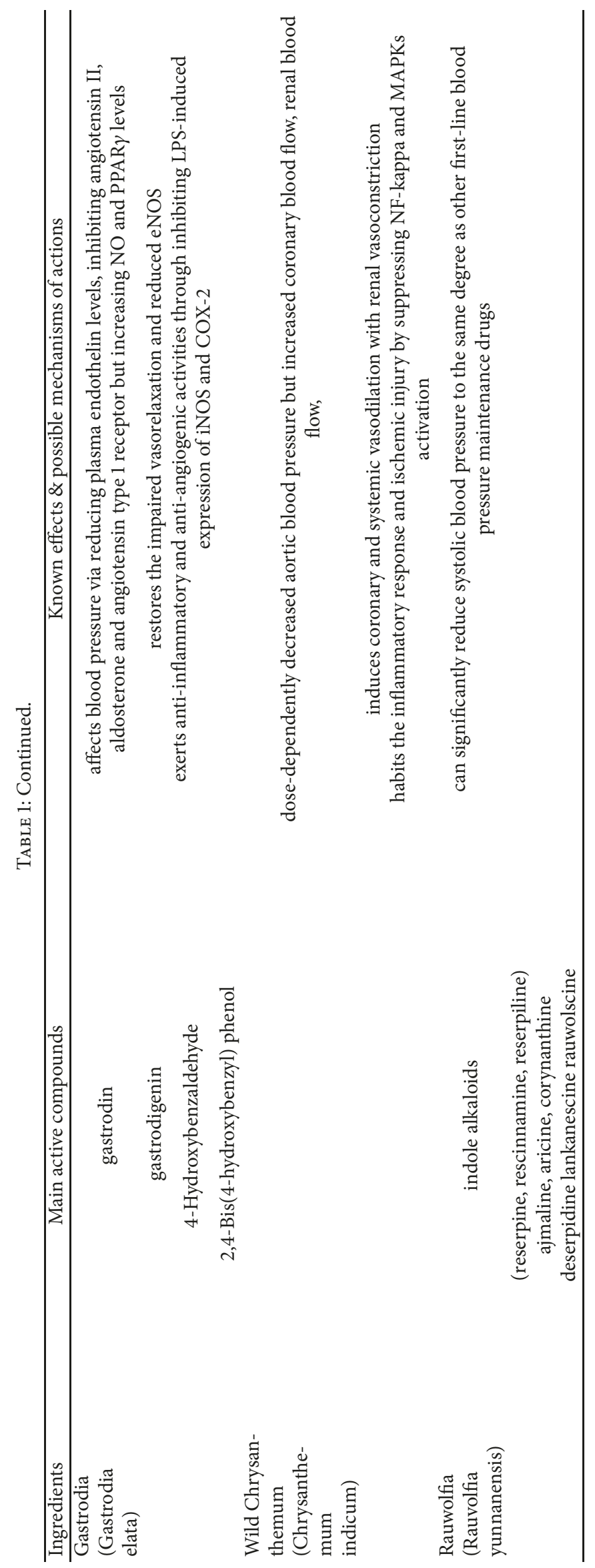


a potential dropout rate of $20 \%$, at least 49 people would be required for each group of the study. We enrolled 50 people each for the test group and control group.

The recruitment of the participants into the study was started on December 7, 2011, and completed on December 30, 2011. The last follow-up observation was completed on March 30, 2012, at Tang Qiao Community Health Service Center in Pudong New District in Shanghai, China. Participants were recruited by self-referral in response to media coverage and word of mouth. Witten informed consent was obtained from all participants prior to enrollment into the study. This study was conducted in adherence to CONSORT guidelines (http://www.consort-statement.org/). All study procedures were conducted in accordance with the Helsinki Declaration of 1975 and were approved by the Shanghai Jiao Tong University Medical Center Institutional Review Board. Subjects who met the first and one of the other two following criteria were eligible for the study:

Inclusion Criteria. (1) Inclusion criteria were as follows: healthy males or females at least 50 years of age; (2) having current prehypertension (systolic blood pressure 130$139 \mathrm{mmHg}$ or diastolic blood pressure $85-89 \mathrm{mmHg}$ ); (3) having a history of hypertension (systolic blood pressure 140$159 \mathrm{mmHg}$ or diastolic blood pressure $90-99 \mathrm{mmHg}$ ).

Exclusion Criteria. (1) Exclusion criteria were as follows: having diagnosed with any severe medical conditions or complications of the brain, liver, kidneys, heart or lungs, any other organs, or malignant tumors that need medical treatments. The exclusion criteria were to ensure that the study would not be affected by the treatment of other illnesses.

2.2. Randomization and Blindness. Participants were randomly assigned to the HyperBalance treatment or placebo treatment. The randomization was performed using a predetermined randomization code, which was generated by a random number generator.

Trial participants and community doctors were both blinded from the treatment (double-blind trial). Of the 100 enrolled participants, 98 participants completed the 12-week follow-up, including 50 subjects in the HyperBalance group and 48 subjects in the placebo group. Two subjects of the placebo group withdrew from the study (due to the objection of the family members).

The participants received similar-looking capsules in color-coded bottles (white bottles for HyperBalance and yellow bottles for placebo). Neither the subjects nor the medical doctors, including the study principal investigator, knew the specific color code until the end of the study. Both the HyperBalance capsules and the placebo (which was mainly composed of flour) were manufactured by Robinson Pharma, Inc. (Costa Mesa, California, USA). Each participant was instructed to take 1 capsule with a meal, two times per day for 12 weeks, and a new batch of supplements was dispensed every month during follow-up sessions.
Table 1 lists the herbal extracts that have known to have supportive properties for blood pressure and are active ingredients of HyperBalance, the formulation used in this study. The key ingredients include extracts of Apocynum (Apocynum venetum) leaves, Gou teng (Uncaria rhynchophylla), Eucommia (Eucommia ulmoides), Heal all (Prunella vulgaris), Senna (Cassia obtusifolia), Gastrodia (Gastrodia elata), Wild chrysanthemum (Chrysanthemum indicum L.), and Rauwolfia (Rauvolfia yunnanensis) (Table 1).

\subsection{Evaluation of Blood Pressure, Treatment-Related Symp-} toms, and Quality of Life. Changes in blood pressure, treatment-related symptoms including headache, dizziness, ringing/buzzing in ears, rapid heart rate, and chest tightness, and other signs were recorded using a medical questionnaire that included the demographics and medication history of the participants and questionnaire and quality of life evaluation form (SF-36) before and after the completion of the intervention. Measurement of baseline blood pressure and the final blood pressure after the completion of the 12-week follow-up observation were repeated twice separated by 1week interval. Blood pressure measurement of siting position was conducted by well-trained medical doctors of the community health center, using a mercury sphygmomanometer (Model XJ11D, Shanghai Medical Equipment Corporation, Shanghai). Hypertension treatment-related symptoms, i.e., dizziness, headache, ringing/buzzing in ears, rapid heart rate, and chest tightness, were scored using a self-administered 5 -point scale $(0=$ no symptoms; $1=$ occasional slight symptoms; $2=$ =mild symptoms; $3=$ moderate symptom; $4=$ severe symptom). The quality of life was evaluated using the SF-36 that contains 8 domains including physical functioning $(\mathrm{PF})$, role physical (RP), bodily pain (BP), general health $(\mathrm{GH})$, vitality (VT), social functioning (SF), role emotional (RE), and mental health $(\mathrm{MH})$. Items were summed per domain and transformed into scores of 0-100, with higher values representing better functioning. Physical composite score (PCS) and mental composite score (MCS) were computed according to each domain score and the data of Chinese adults model [35]. PCS and MCS were associated with chronic disease, walking and visual abilities, sleep quality, marital status, alcohol consumption, smoking, filial piety, ethnicity, and dietary habits [36]. All participants were followed up each month in order to check compliance and adverse effects.

2.4. Statistics Analysis. EpiData 3.02 software was used for the establishment of the database. SPSS 20 software was used for statistical analysis. Group data were presented as the mean \pm s.d. Differences between the HyperBalance and placebo groups were compared using Student's t-test for quantitative variables with normal distribution, or Chi-square test for categorized variables. Ridit scoring test, which is a nonparametric test for comparing two or more sets of ordered qualitative data, was used for evaluating the changes in the symptom severity scores after the intervention. The alpha level of $\mathrm{P}>0.05$ was chosen as being statistically significant. All p-values reported were 2 -sided. 


\section{Results}

3.1. Participants' Demographic Characteristics. The baseline characteristics of age, gender, and histories of alcohol intake, disease, and medication of the participants are shown in Table 2. There were 16 males (32\%) and 34 females (68\%) in the HyperBalance group, and 22 males (45.8\%) and 26 females $(54.2 \%)$ in the placebo group. The gender distribution between the two groups was not significantly different between the two groups $\left(\chi^{2}=1.97, \mathrm{P}>0.05\right)$, with females accounting for more than two-thirds of all participants. The average age of all participants was $65.1 \pm 7.1$, and again no significant difference was found between the HyperBalance group (64.97 \pm 7.2 years) and the placebo group (65.28 \pm 7.1 years) $(\mathrm{t}=0.212, \mathrm{P}>0.05)$.

The HyperBalance and placebo groups also showed similar baseline distribution patterns of alcohol drinking (12\% vs. $10.4 \%)\left(\chi^{2}=0.06, \mathrm{P}=0.804\right)$, smoking ( $16 \%$ vs. $\left.10.4 \%\right)$ $\left(\chi^{2}=0.664, \mathrm{P}=0.415\right)$, proportions of prehypertension $(82 \%$ vs. $83.3 \%)\left(\chi^{2}=0.03, \mathrm{p}=0.862\right)$, hypertension $(18 \%$ vs $16.7 \%)$ $\left(\chi^{2}=0.03, \mathrm{p}=0.862\right)$, and antihypertension medication $(78 \%$ vs. $87.5 \%)\left(\chi^{2}=1.542, \mathrm{P}=0.214\right)$. There were three cases of hyperlipidemia in each group (Table 2 ).

3.2. Blood Pressure. The mean values of systolic blood pressure (SBP) and diastolic blood pressure (DBP) of both the HyperBalance group and the placebo group before and after the 12-week intervention are shown in Table 3. There were no baseline differences between HyperBalance and placebo controls before the 12-week intervention in SBP (136.18 \pm 4.38 $\mathrm{mmHg}$; vs $135.79 \pm 4.22 \mathrm{mmHg}, \mathrm{P}>0.05)$, or DBP $(82.45 \pm 2.91$ $\mathrm{mmHg}$ vs. $82.90 \pm 3.07 \mathrm{mmHg}, \mathrm{P}>0.05$ ) (Table 3 ). However, the SBP and DBP became significantly lower in HyperBalance group than in the placebo group after 3 months of HyperBalance intervention $(124.14 \pm 3.96 \mathrm{mmHg}$ vs. $132.35 \pm 4.65$ $\mathrm{mmHg}, \mathrm{P}<0.01$ and; $80.24 \pm 2.41 \mathrm{mmHg}$ vs. $8 \quad 82.27 \pm 3.01$ $\mathrm{mmHg}, \mathrm{P}<0.01$, respectively) (Table 3 ).

3.3. Hypertension Treatment-Related Symptoms. There were no baseline differences between HyperBalance group and placebo control in symptom severity scores of dizziness $(2.32 \pm 0.55$; vs $2.42 \pm 0.50, \mathrm{P}>0.05)$, headache $(2.22 \pm 0.62$; vs $2.31 \pm 0.59, \mathrm{P}>0.05)$, ringing/buzzing in ears (1.02 \pm 0.32 ; vs $1.08 \pm 0.28, \mathrm{P}>0.05)$, and rapid heart rate and chest tightness $(0.96 \pm 0.20$; vs $0.98 \pm 0.14, \mathrm{P}>0.05)$ (Table 4$)$. However, after 3 months of HyperBalance intervention, all symptom severity scores became significantly lower in the HyperBalance group than in the placebo group: dizziness $(0.82 \pm 0.44$; vs $2.02 \pm 0.64$, $\mathrm{P}<0.01)$; headache $(0.46 \pm 0.50$; vs $1.81 \pm 0.61, \mathrm{P}<0.01)$; ringing/buzzing in ears $(0.44 \pm 0.50$; vs $1.04 \pm 0.29, \mathrm{P}<0.01)$; and rapid heart rate and chest tightness $(0.30 \pm 0.46$; vs $0.92 \pm 0.28$, $\mathrm{P}<0.01$ ) (Table 4 ), primarily due to a greater symptom severity reduction in the HyperBalance group.

To better evaluate the overall effects of HyperBalance on hypertension-related symptoms, the combined symptom severity scores of dizziness, headache, ringing/buzzing in ears, and rapid heart rate and chest tightness were analyzed. The baseline values in combined symptoms scores were not significant between the HyperBalance and placebo groups $(6.56 \pm 1.29$ vs. $6.91 \pm 1.23, \mathrm{P}>0.05)$. However, the combined scores became significant between the two groups after the intervention $(2.04 \pm 1.47$ vs. $5.79 \pm 1.41)(\mathrm{P}<0.001)$ (Table 4$)$.

The combined scores of the 4 symptoms were further pooled into 3 subgroups based on levels of symptom improvement (0-2, slight-mild; 3-4, moderate; 5-7 great) for Chisquare analysis. In the HyperBalance group, $48 \%$ people showed great symptom severity improvement (5-7 points) and $42 \%$ people showed moderate symptom improvement (3-4 points) compared to $2.1 \%$ and $14.6 \%$ in the placebo group, respectively $(\mathrm{P}<0.01)$, whereas $48.0 \%$ of the placebo group showed no symptoms improvement ( 0 point) and $36 \%$ showed slight symptom improvement (1-2 points). Ridit scoring test showed a significantly greater improvement in the combined symptom severity scores after the HyperBalance intervention $($ mean $=0.719 \pm 0.1 .73)$ than after placebo intervention $(0.272 \pm 0.183)(\mathrm{t}=12.406, \mathrm{P}<0.001)$ (Tables 5 and $6)$.

3.4. Quality of Life. No significant differences were found between the HyperBalance and placebo groups in the baseline values of the different health domains of SF-36 before and after the 3-month intervention. The scores of PF, BP, GH, and VT, however, became significantly increased in the HyperBalance group after the 3-month intervention. The scores of POS and MCS also became significantly higher in HyperBalance and placebo groups after the 3-month intervention, suggesting improved quality of life in the HyperBalance group (Table 7).

\section{Discussion}

Prehypertension and hypertension each affect about $30 \%$ of the world adult population and increase the risk of incidents of CVD $[3,5,37]$. According to a 7-year follow-up study of 25,079 prehypertensive people, the annual progression rate of prehypertension to hypertension is more than $5.5 \%$ [38]. Prehypertension is also a major risk for heart attacks, strokes, congestive heart failure, kidney failure, and cognitive decline [39-41]. Most prehypertensive people do not receive effective interventions $[42,43]$. One reason is that many people do not like to take medication to control prehypertension and/or hypertension due to the perceived side effects and potential addiction associated with the drugs [44].

In this exploratory observational study, the effectiveness of 12-week dietary supplementation of a polyherbal formulation, HyperBalance, was evaluated in older adults with prehypertension or with a history of hypertension and drug treatment. The results show that HyperBalance was significantly more effective than placebo in improving blood pressure, resulting in an average reduction of $12.04 \mathrm{~mm} \mathrm{gH}$ for SBP and a reduction of $2.21 \mathrm{~mm} \mathrm{gH}$ for $\mathrm{DBP}$ compared to the $3.43 \mathrm{mmHg}$ reduction for SBP and $0.63 \mathrm{mmHg}$ reduction for DBP by placebo. Moreover, HyperBalance was also more effective than placebo in reducing drug treatment-related symptoms in these old adults. 


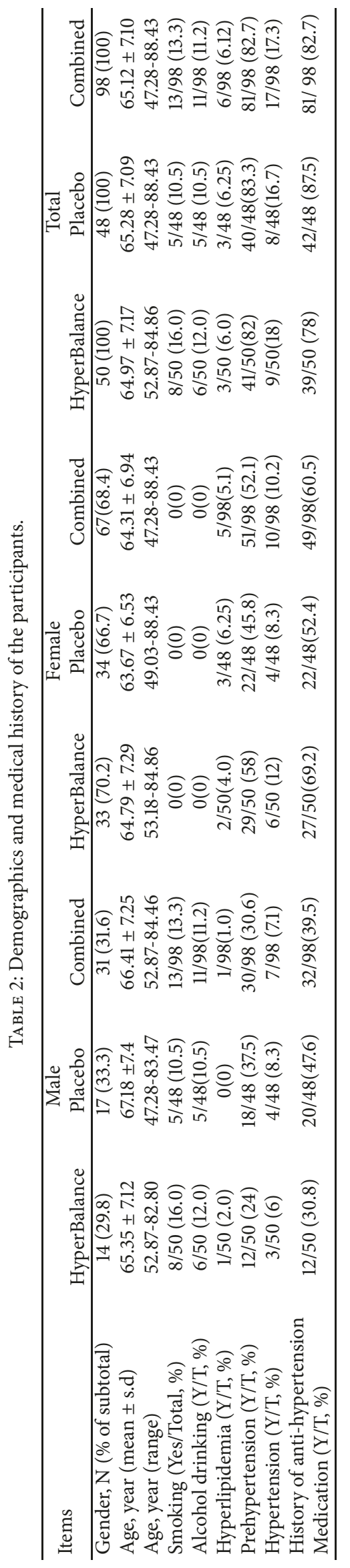


TABLE 3: Blood pressure before and after 12-week of HyperBalance/Placebo intervention (mean \pm s.d).

\begin{tabular}{lcc}
\hline Blood Pressure (mmHg) & Before intervention & After intervention \\
\hline Systolic blood pressure (SBP) & & $124.14 \pm 3.96 *$ \\
HyperBalance & $136.18 \pm 4.38$ & $132.35 \pm 4.65 *$ \\
Placebo & $135.79 \pm 4.22$ & $9.43 /<0.001^{++}$ \\
t / P value & $0.45 / 0.66$ & $80.24 \pm 2.41 *$ \\
Diastolic blood pressure (DBP) & & $82.27 \pm 3.01 *$ \\
HyperBalance & $82.45 \pm 2.91$ & $3.68 /<0.001^{++}$ \\
Placebo & $82.90 \pm 3.07$ & $0.74 / 0.46$ \\
t / P value & & \\
\hline
\end{tabular}

*, $\mathrm{P}<0.05$, comparison of baseline with the post-intervention values within each treatment group;

${ }^{++}, \mathrm{P}<0.001$, difference between Hyperbalance and placebo groups after the 12 -week intervention

TABLE 4: Changes in individual and combined severity scores of anti-hypertension medicine treatment-related symptoms (mean \pm s.d) after 12 weeks of HyperBalance/placebo intervention.

\begin{tabular}{|c|c|c|c|c|}
\hline Group & $\begin{array}{c}\text { Before } \\
\text { intervention }\end{array}$ & $\begin{array}{c}\text { After } \\
\text { intervention }\end{array}$ & $\begin{array}{c}\text { Difference between } \\
\text { before and after } \\
\text { intervention }\end{array}$ & $\mathrm{t} / \mathrm{P}$ value \\
\hline \multicolumn{5}{|l|}{ Dizziness } \\
\hline HyperBalance & $2.32 \pm 0.55$ & $0.82 \pm 0.44 *$ & $1.50 \pm 0.54$ & $19.498 /<0.001$ \\
\hline Placebo & $2.42 \pm 0.50$ & $2.02 \pm 0.64 *$ & $0.40 \pm 0.57$ & $4.779 /<0.001$ \\
\hline $\mathrm{t} / P$ value & $0.91 / 0.37$ & $10.94 /<0.001$ & $9.778 /<0.001^{++}$ & \\
\hline \multicolumn{5}{|l|}{ Headache } \\
\hline HyperBalance & $2.22 \pm 0.62$ & $0.46 \pm 0.503 *$ & $1.76 \pm 0.48$ & $26.124 /<0.001$ \\
\hline Placebo & $2.31 \pm 0.59$ & $1.81 \pm 0.607 *$ & $0.50 \pm 0.58$ & $5.937 /<0.001$ \\
\hline $\mathrm{t} / P$ value & $0.76 / 0.45$ & $12.03 /<0.001^{++}$ & $11.683 /<0.001^{++}$ & \\
\hline \multicolumn{5}{|c|}{ Ringing/buzzing in ears } \\
\hline HyperBalance & $1.02 \pm 0.32$ & $0.44 \pm 0.501 *$ & $0.58 \pm 0.54$ & $7.624 /<0.001$ \\
\hline Placebo & $1.08 \pm 0.28$ & $1.04 \pm 0.29$ & $0.04 \pm 0.20$ & $1.430 / 0.159$ \\
\hline $\mathrm{t} / P$ value & $1.04 / 0.30$ & $7.24,<0.01$ & $6.608 /<0.001^{++}$ & \\
\hline \multicolumn{5}{|c|}{ Rapid heart rate and chest tightness } \\
\hline HyperBalance & $0.96 \pm 0.20$ & $0.30 \pm 0.46 *$ & $0.66 \pm 0.48$ & $9.753 /<0.001$ \\
\hline Placebo & $0.98 \pm 0.14$ & $0.92 \pm 0.28$ & $0.06 \pm 0.24$ & $1.770 / 0.083$ \\
\hline $\mathrm{t} / P$ value & $0.55,0.59$ & $7.94,<0.001$ & $7.828 /<0.001^{++}$ & \\
\hline \multicolumn{5}{|c|}{ Combined symptom scores } \\
\hline HyperBalance & $6.52 \pm 1.27$ & $2.02 \pm 1.46 *$ & $4.50 \pm 1.36$ & $23.414 /<0.001$ \\
\hline Placebo & $6.79 \pm 1.07$ & $5.79 \pm 1.41 *$ & $1.00 \pm 1.29$ & $5.378 /<0.001$ \\
\hline $\mathrm{t} / P$ value & $1.145 / 0.255$ & $12.967 /<0.001$ & $13.074 /<0.001^{++}$ & \\
\hline
\end{tabular}

$*, \mathrm{P}<0.05$, comparison of baseline with the post-intervention values within each treatment group;

${ }^{++}, \mathrm{P}<0.001$, comparison of the difference between Hyperbalance and placebo groups after the 12 -week intervention.

TABLE 5: Different impact of HyperBalance and placebo on combined blood pressure severity scores.

\begin{tabular}{lccc}
\hline Group & Mild change $(0-2) *$ & Moderate $(3-4) * *$ & Large change $(5-8) * * *$ \\
\hline HyperBalance, $\mathrm{n}(\%)$ & $5(10)$ & $21(42)$ & $24(48)$ \\
Placebo $(\%)$ & $40(83.3)$ & $7(14.6)$ & $1(2.1)$ \\
$\chi^{2} / \mathrm{P}$ & & $55.364 /<0.01$ & \\
\hline
\end{tabular}

*0-2 points: none to mild symptom severity score reduction

$* * 3-4$ points: moderate symptom severity score reduction

$* * * 5-8$ points: large symptom severity score reduction. 
TABLE 6: Different impact of HyperBalance and placebo on combined blood pressure severity scores.

\begin{tabular}{lcccccc}
\hline \multirow{2}{*}{ Score Change } & \multicolumn{2}{c}{ HyperBalance } & \multicolumn{2}{c}{ Placebo } & \multicolumn{2}{c}{ Total } \\
& $\mathrm{N}$ & $\%$ & $\mathrm{~N}$ & $\%$ & $\mathrm{~N}$ & $\%$ \\
\hline 0 & 0 & 0 & 23 & 48 & 23 & 23 \\
$1+$ & 0 & 0 & 8 & 17 & 8 & 8 \\
$2+$ & 5 & 10 & 9 & 19 & 14 & 14 \\
$3+$ & 5 & 10 & 6 & 13 & 11 & 11 \\
$4+$ & 16 & 32 & 1 & 2 & 17 & 17 \\
$5+$ & 9 & 18 & 0 & 0 & 9 & 9 \\
$6+$ & 13 & 26 & 1 & 2 & 14 & 14 \\
$7+$ & 2 & 4 & 0 & 0 & 2 & 2 \\
Total & 50 & 100 & 48 & 100 & 98 & 100 \\
\hline$t$ (Ridit scoring test) & \multicolumn{7}{c}{12.406} & & & \\
P value & $<0.001$ & & & \\
\hline
\end{tabular}

HyperBalance appears to have improved blood pressures to some degree in all participants, including the 23 of the 41 prehypertensive people who were reversed to normal blood pressure and the 9 hypertensive people who were reversed to prehypertension status. In comparison, only 1 of the 40 prehypertensive people of the placebo group was reversed to normal blood pressure and only 4 of the 8 hypertension people showed reduced blood pressure. Furthermore, a greater proportion of the HyperBalance group showed greater improvement in drug treatment-related symptoms including dizziness, headache, ringing/buzzing in ears, and rapid heart rate and chest tightness, as well as quality of life.

These results suggest that that supplementation of polyherbal ingredients such as HyperBalance could benefit people with prehypertension/hypertension and treatment-related symptoms. Although the underlying mechanism of HyperBalance remains unknown, each of the active polyherbal ingredients could have synergistically contributed to the efficacy of HyperBalance.

Our study also shows that the herbal ingredients of HyperBalance share similar yet distinct antioxidant, antiinflammatory, antiproliferation, antisuperoxide, and NOpromoting properties. Their potential actions are in agreement with the current knowledge that accelerated inactivation of $\mathrm{NO}$ and SOD, and elevated renal damage due to increased norepinephrine, angiotensin II, endothelin, and superoxide anion, increased vascular smooth muscle cell proliferation, decreased antioxidant capacity, and are related to the hypertrophy and reduction in outer diameter of the arteries and the development of hypertension [18]. Meanwhile, antioxidant treatment reduces arterial pressure, aortic superoxide production, and renal inflammation in DOCAsalt rats and decreases blood pressure and aortic superoxide release and increases bioactive nitric oxide in SHR strokeprone rats [15].

Chrysanthemum indicum Linne (CIL) contains flavonoids, 1,8-cineole, camphor, borneol, and bornyl acetate as the main active compounds $[45,46]$. Intravenous administration of CIL extract at the dosage of $5-20 \mathrm{mg} / \mathrm{kg}$ decreased aortic blood pressure but increased coronary blood flow, renal blood flow, left ventricular $\mathrm{dP} / \mathrm{dt}$, and heart rate in the dog in a dose-dependent manner [47]. CIL directly and uniformly induced coronary and systemic vasodilation with renal vasoconstriction [48]. CIL extract inhibited the inflammatory response by suppressing NF-kappa B and MAPKs activation in lipopolysaccharide-induced RAW 264.7 macrophages [49]. Pretreatment of CIL attenuated neuronal damage/death in the brain after cerebral ischemia/reperfusion via an antiinflammatory approach [50].

The main active ingredients of Apocynum venetum leaves (AVLE) include apocynin, flavonol glycosides, quercetin, triacontanol, beta-sitosterol, hyperin, and long-chain fatty acids (Table 1). AVLE has blood pressure effects in spontaneously hypertensive rats (SHR), renal hypertensive rats, and $\mathrm{NaCl}$-induced hypertensive rats, due to amelioration of the kidney dysfunctions, inhibition of ROS, and oxidation of low-density lipoprotein (LDL) $[18,51,52]$. AVLE exerts its effect on blood pressure via dilating the blood vessels in an endothelium- and concentration-dependent manner with optimal effect seen at $10 \mu \mathrm{g} / \mathrm{mL}$, primarily due to its NO-releasing, superoxide-scavenging and NADPH oxidase inhibiting properties [53]. AVLE also possesses antioxidant and anti-lipid peroxidation effects. Apocynin increases glutathione synthesis and activates AP-1 in alveolar epithelial cells and prevents ischemia-reperfusion lung injury $[54,55]$. Deoxycorticosterone acetate- (DOCA-) salt hypertension and venoconstriction are characterized by low renin/angiotensin but increased arterial superoxide levels, arterial endothelin-1 (ET-1), NADPH oxidase activation, and superoxide generation, all of which can be reversed by AVLE [56]. AVLE and its purified components can strongly inhibit the formation of advanced glycation end products (AGEs), which are involved in the pathogenesis of diabetic vascular complications and atherosclerosis [57].

Uncaria rhynchophylla has long been used in Chinese medicine to treat cardiovascular disorder, hypertension, headaches, and other cognitive concerns [58, 59]. Various compounds including indole alkaloids (rhynchophylline and isorhynchophylline, triterpenes), flavonoids, phenols, and phenylpropanoids have been isolated with indole alkaloids as the main efficacy component for hypertension. Rhynchophylline and isorhynchophylline exert endotheliumindependent vasodilatory effects that are mediated by Ltype Ca2+ channels [60]. Isorhynchophylline can inhibit endotoxemic, vascular smooth muscle cell proliferation (a process that involves the development of blood pressure) through increased NO production and cell cycle regulation $[61,62]$.

Eucommia ulmoides (EU) contains various chemical constituents such as lignans, iridoids, phenolics, steroids, and flavonoids that have multiple antioxidant, anti-inflammatory, antiallergic, antimicrobial, anticancer, antiaging, cardioprotective, and neuroprotective properties [63]. Eucommia ulmoides lignans are effective in lowering blood pressure, protecting against hypertensive renal injury in spontaneous hypertensive rats, and inhibiting aldose reductase (AR) overexpression in the kidney [64]. Eucommia lignans inhibit angiotensin II- (Ang II-) induced proliferation of rat mesangial cells via regulating cell cycle-related genes P21 and P27 
TABLE 7: Changes in SF-36 scores after the 3 month-intervention.

\begin{tabular}{lcccc}
\hline \multirow{2}{*}{ Items } & \multicolumn{2}{c}{ Before intervention } & \multicolumn{2}{c}{ After intervention } \\
& HyperBalance & Placebo & HyperBalance & $91.25 \pm 2.19$ \\
\hline PF & $90.7 \pm 3.2$ & $91.15 \pm 2.36$ & $91.1 \pm 2.73 *$ & $100 \pm 0$ \\
RP & $100 \pm 0$ & $100 \pm 0$ & $100 \pm 0$ & $80.17 \pm 8.83$ \\
BP & $78.02 \pm 8.16$ & $79.21 \pm 6.79$ & $83.22 \pm 11.38 * *$ & $50.9 \pm 8.2$ \\
GH & $49.78 \pm 4.97$ & $50.6 \pm 5.39$ & $51.88 \pm 8.8 * *$ & $87.4 \pm 3.42$ \\
VT & $86.7 \pm 3.29$ & $87.19 \pm 3.98$ & $87.4 \pm 3.07 *$ & $100 \pm 0$ \\
SF & $99.25 \pm 3.92$ & $100 \pm 0$ & $99.75 \pm 1.77$ & $100 \pm 0$ \\
RE & $100 \pm 0$ & $100 \pm 0$ & $100 \pm 0$ & $88.25 \pm 5.11$ \\
MH & $87.36 \pm 4.6$ & $88.33 \pm 5.77$ & $87.76 \pm 4.15$ & $50 \pm 5.16$ \\
HT & $48.5 \pm 6$ & $50.52 \pm 3.61$ & $48.5 \pm 6$ & $75.63 \pm 4.41 * *$ \\
PCS & $66.88 \pm 3.75$ & $76.8 \pm 4.88$ & $67.53 \pm 3.71 * *$ & $81.8 \pm 2.3 * *$ \\
MCS & $68.24 \pm 3.37$ & $69 \pm 4$ & $89 \pm 3.42 * *$ \\
\hline
\end{tabular}

$* \mathrm{P}<0.05$, within treatment group changes after 3 -month intervention

$* * \mathrm{P}<0.01$, within treatment group changes after 3-month intervention.

[65] and exert their antihypertensive effects via regulating NO and renin-angiotensin system (RAS) and direct artery relaxing effect [66]. Cellular proliferation is an important pathological factor in hypertensive renal injuries, and increased Ang II expression was essential for target-organ damage during hypertension. Ang II is the main effective peptide in the RAS and is a key mediator in the development of hypertensive nephropathy [67].

Prunella vulgaris ( $P$. vulgaris) leaves (PVL) have been widely consumed as a tea ingredient since ancient times for its antiviral, antibacterial, anti-inflammatory, antiallergic, antioxidative, antitumor, antihypertensive, antihyperglycemic, and immunoregulatory properties [68-71]. Triterpenoic acids, flavonoids, phenolics, and diterpene are the major active compounds. APL treatment (100 and 200 $\mathrm{mg} / \mathrm{kg} /$ day) for eight weeks markedly lowered systolic blood pressure, blood glucose, total plasma cholesterol, triglyceride, LDL-cholesterol, malondialdehyde, and TGF-betal but improved total NO level, HDL-cholesterol level, and diabetic vascular dysfunction in high-fat high cholesterol mice with type 2 diabetes [72]. P. vulgaris dose-dependently ameliorated vascular constriction of aortic rings induced by acetylcholine or SNP [72]. Ursolic acid in PVL stimulates blood circulation via inhibition of $\mathrm{Na}+/ \mathrm{K}+$-ATPase [73]. PVL also dosedependently inhibited high glucose- (HG-) induced expression of cell adhesion molecules (ICAM-1, VCAM-1, and Eselectin) in human umbilical vein endothelial cells, inhibited HG-induced adhesion, and suppressed p65 NF-kappa B activation in HL-60 monocytic cells, as well as inhibiting the formation of intracellular reactive oxygen species (ROS) [74] and the proliferation of vascular smooth muscle cells [75]. PVL inhibits proinflammatory cytokines, NF-kappa B, and mast cell-derived immediate-type allergic reactions [76] and shows antihyperglycemic activity in streptozotocin-induced diabetic mice [77]. PVL extract stimulates macrophage phagocytic activity, nitric oxide (NO) production, and cytostatic activity and induces gene expression and macrophagerelated TNF-alpha, IL-1beta, and IL-6 [78]. Rosmarinic acid (RA) of PVL inhibits inflammatory response, LPS-induced cyclooxygenase-2 (COX-2), and iNOS protein expression [79].

Senna (Cassia obtusifolia) oral administration of obtusifolin extracts significantly ameliorated high-fat diet-induced changes in body weight, total cholesterol, triglyceride, low-density lipoprotein cholesterol, high-density lipoprotein cholesterol, and malondialdehyde but increased serum superoxide dismutase and nitric oxide [80]. Naphthopyrone glycosides from Cassia obtusifolia have antiallergic effect by inhibiting histamine release [33], and anthraquinones from seeds of Cassia obtusifolia are potent inhibitors of platelet aggregation [34].

Rauwolfia yunnanensis contains alkaloids (reserpine, rescinnamine, reserpiline), ajmaline, aricine, corynanthine, deserpidine, lankanescine, rauwolscine, etc. as the main active compounds [81]. Rserpine is as effective as other firstline antihypertensive drugs in reducing SBP $[82,83]$ and it was widely used in the 1950 s for treatment of hypertension. Reserpine can effectively reduce blood pressure, depress the activity of the central nervous system, and act as hypnotics [25]. Now only low dose of Rauwolfia is used as a cotreatment of hypertension due to its side effects such as oxidative damage to liver and other organs and depression [84].

So far, few studies compared single medical herbal ingredients with polyherbal formulation on prehypertension although combination therapy of different antihypertensive agents often results in better efficacy than single-pills therapy [85]. One recent study showed that 6-month supplementation of a mostly Rauwolfia serpentine formulation (plus several other herbal-mineral ingredients) in 30 adults with prehypertension or stage I hypertension significantly increased serum potassium $(\mathrm{p}<0.05)$ but significantly decreased systolic blood pressure $(\mathrm{p}<0.0001)$ and diastolic blood pressure $(\mathrm{p}<$ $0.0001)$ [25]. While no serious adverse events were reported, $30 \%$ of the participants withdrew from the citing potential side effects including nasal congestion or fatigue as the most common side effects [25].

One early study examined 295 moderate arterial hypertension patients with the diastolic pressure under $110 \mathrm{~mm}$ 
$\mathrm{Hg}$ [29]. Of these, 103 patients who received early hypotensive therapy of rauwolfia drugs (13 patients also received additional hypothiazide) showed decrease in arterial blood pressure to normal level and an 8-year increase in mean lifespan compared to the 80 patients who had not received any hypotensive drugs. Furthermore, the number of fatal brain strokes and myocardial infarctions decreased almost 2fold in the treatment group.

In this study, a significant proportion $(82.7 \%)$ or 81 of the 98 participants received the antihypertension medicine amlodipine tablet for a period between 3 and 36 months. Amlodipine is a calcium channel blocker that dilates (widens) blood vessels and improves blood flow but it may also induce treatment-related symptoms. It is known that antihypertension medicines can induce different side effects such as dizziness, weakness, fatigue, shortness of breath, difficulty breathing, and chest pain induced by beta-blockers, headache, dizziness, fainting, reduced kidney function induced by ACE Inhibitors, and affected muscular function of the heart by diuretics $[72,74,75,80,86-92]$. Further studies could validate the beneficial effects of polyherbal ingredients in managing prehypertension/hypertension and treatment-related symptoms.

There are limitations of this study. The sample size of this study is too small to reach a conclusion. Because risk factors for prehypertension/hypertension are heterogeneous and potentially affected by a range of genetic and environmental factors including lifestyle, daily activity/exercise, genotype, age, obesity, diabetes, stress, education level, inflammation, alcohol intake, and smoking, it is difficult to know the optimal dose of individual ingredients for a most effective formulation. Further studies could control these factors to allow a better understanding of the mechanism of polyherbal intervention.

\section{Conclusion}

In conclusion, 12-week supplementation of polyherbal ingredients such as HyperBalance could benefit older adults with prehypertension/hypertension in improving blood pressures and treatment-related symptoms. Further studies of longterm supplementation of polyherbal medicine are needed to validate the current findings.

\section{Abbreviations}

ALD: Aldosterone

Ang II: Angiotensin II

AVLE: Apocynum venetum leaves

BMI: Body mass index

BP: $\quad$ Bodily pain

CIL: Chrysanthemum indicum Linne

COX-2: Cyclooxygenase-2

CVD: For cardiovascular disorders

DBP: Diastolic blood pressure

DOCA: Deoxycorticosterone acetate

EG: $\quad$ Gastrodia elata

eNOS: Endothelial nitric oxide synthase
E-selectin: $\quad$ A cell surface molecule involved in immune adhesion and cell trafficking

ET: $\quad$ Endothelin

EU: $\quad$ Eucommia ulmoides

GH: General health

HG: High glucose

HyperBalance: A polyherbal extracts-based formulation

ICAM-1: $\quad$ Intercellular adhesion molecule 1 (cell adhesion molecules)

iNOS: $\quad$ Inducible nitric oxide synthase

LDL: $\quad$ Low-density lipoprotein

MAPK: Mitogen-activated protein kinase

MCS: $\quad$ Mental composite score

$\mathrm{MH}: \quad$ Mental health

NADPH: Nicotinamide Adenine Dinucleotide phosphate (reduced form)

NF-kappaB: $\quad$ Nuclear factor

kappa-light-chain-enhancer of activated B cells

NO: $\quad$ Nitric oxide

PCS: $\quad$ Physical composite score

PF: $\quad$ Physical functioning

PPAR $\gamma$ : Peroxisome proliferate-activated receptor gamma

PVL: $\quad$ Prunella vulgaris (P. vulgaris) leaves

RA: Rosmarinic acid

RE: $\quad$ Role emotional

ROS: $\quad$ Reactive oxygen species

RP: Role physical

SBP: $\quad$ Systolic blood pressures

SF: $\quad$ Social functioning

SHRSP: $\quad$ Stroke-prone spontaneously

hypertensive rats

SOD: $\quad$ Superoxide dismutase

TCM: Traditional Chinese medicine

TGF-betal: $\quad$ Transforming growth factor betal

VCAM-1: $\quad$ Vascular cell adhesion molecule 1

ventricular $\mathrm{dP} / \mathrm{dt}$ : Measures of left ventricle (LV) pressure

VT: Vitality.

\section{Data Availability}

The raw data is not publicly available. However, the raw data could be available from the corresponding authors upon reasonable request and with permission of the study sponsor.

\section{Ethical Approval}

All study procedures were conducted in accordance with the Helsinki Declaration of 1975 and were approved by the Shanghai Jiao Tong University School of Public Health.

\section{Consent}

Informed consent was obtained from all participants prior to enrollment into the study. 


\section{Disclosure}

The founders had no role in the design, perform, and results interpretation of the study.

\section{Conflicts of Interest}

The authors declare that they have no competing interests.

\section{Authors' Contributions}

Tian Shen, Jingfen Zhu, Yong Cai, Gang Xu, Jianyu Rao, and Rong Shi contributed to the experimental design and implementation. Donghua Li, Tian Shen, Jingfen Zhu, Yong Cai, Gang $\mathrm{Xu}$, and Yi Feng contributed to the participant enrollment, evaluation, and follow up. Tian Shen, Jingfen Zhu, Yi Feng, Donghua Li, and Shuxian Zhang contributed to the data collection. Tian Shen, Jingfen Zhu, and Guoqiang Xing contributed to the data analysis. Guoqiang Xing contributed to the literature search and manuscript preparation. Tian Shen, Guoqiang Xing, and Jingfen Zhu are equal contributors. All authors have read and approved the manuscript.

\section{Acknowledgments}

Ms. Mina Shariff and Mr. Tuong Nguyen are acknowledged for their sponsors' role in funding this study (DRM Resources (Costa Mesa, California, USA). The authors thank Mr. Evan Xing for proofreading the manuscript. This study was sponsored, in part, by DRM Resources (Costa Mesa, California, USA), National Natural Science Foundation of China (7163187), The Sciences \& Technology Bureau of Sichuan Province (KY-1720), the Social Cognitive and Behavioral Sciences Program of Shanghai Jiao Tong University (14JCRY03), Shanghai Key Discipline Construction Project in Public Health (15GWZK1002), and The Sciences \& Technology Bureau of Sichuan Province (KY-1720).

\section{References}

[1] T. Nwankwo, S. Yoon, V. Burt, and Q. Gu, "Hypertension among adults in the US: National Health and Nutrition Examination Survey," NCHS Data Brief, No. 133. Hyattsville, MD: National Center for Health Statistics, Centers for Disease Control and Prevention, US Dept of Health and Human Services, 2013.

[2] X. Meng, G. Dong, D. Wang et al., "Prevalence, awareness, treatment, control, and risk factors associated with hypertension in urban adults from 33 communities of China: the CHPSNE study," Journal of Hypertension, vol. 29, no. 7, pp. 1303-1310, 2011.

[3] L. Yang, J. Yan, X. Tang, X. Xu, W. Yu, and H. Wu, "Prevalence, awareness, treatment, control and risk factors associated with hypertension among adults in Southern China, 2013," PLoS ONE, vol. 11, no. 1, Article ID e0146181, 2016.

[4] D. Mozaffarian, E. J. Benjamin, A. S. Go et al., "Heart disease and stroke statistics-2016 update: a report from the American Heart Association," Circulation, vol. 133, no. 4, pp. e38-e360, 2016.

[5] G. Yang, Y. Ma, S. Wang et al., "Prevalence and correlates of prehypertension and hypertension among adults in Northeastern China: a cross-sectional study, International Journal of
Environmental Research and Public Health, vol. 13, no. 1, p. 82, 2016.

[6] H. Arima, C. Anderson, T. Omae et al., "Degree of blood pressure reduction and recurrent stroke: The PROGRESS trial," Journal of Neurology, Neurosurgery \& Psychiatry, vol. 85, no. 11, pp. 1284-1285, 2014.

[7] A. H. Association, Prehypertension Triples Heart Attack Risk, 2005.

[8] R. S. Vasan, M. G. Larson, E. P. Leip et al., "Impact of highnormal blood pressure on the risk of cardiovascular disease," The New England Journal of Medicine, vol. 345, no. 18, pp. 12911297, 2001.

[9] J. Sorof and S. Daniels, "Obesity hypertension in children: a problem of epidemic proportions," Hypertension, vol. 40, no. 4, pp. 441-447, 2002.

[10] J. M. Sorof, T. Poffenbarger, K. Franco, L. Bernard, and R. J. Portman, "Isolated systolic hypertension, obesity, and hyperkinetic hemodynamic states in children," Journal of Pediatrics, vol. 140, no. 6, pp. 660-666, 2002.

[11] W. Li, Y. Liu, J. Wang et al., ““Angiotensin II memory” contributes to the development of hypertension and vascular injury via activation of NADPH oxidase," Life Sciences, vol. 149, pp. 18-24, 2016.

[12] B. Lopez, M. G. Salom, B. Arregui, F. Valero, and F. J. Fenoy, "Role of superoxide in modulating the renal effects of angiotensin II," Hypertension, vol. 42, no. 6, pp. 1150-1156, 2003.

[13] D. A. Lawlor and G. D. Smith, "Early life determinants of adult blood pressure," Current Opinion in Nephrology and Hypertension, vol. 14, pp. 259-264, 2005.

[14] F. Perticone, A. Sciacqua, R. Maio et al., "Endothelial dysfunction, ADMA and insulin resistance in essential hypertension," International Journal of Cardiology, vol. 142, no. 3, pp. 236-241, 2010.

[15] R. D. Manning Jr., N. Tian, and S. Meng, "Oxidative stress and antioxidant treatment in hypertension and the associated renal damage," American Journal of Nephrology, vol. 25, no. 4, pp. 311317, 2005.

[16] J. A. Holland, J. W. Meyer, M. Chang, R. W. O’Donnell, D. K. Johnson, and L. M. Ziegler, "Thrombin stimulated reactive oxygen species production in cultured human endothelial cells," Endothelium, vol. 6, no. 2, pp. 113-121, 1998.

[17] J. A. Holland, J. W. Meyer, M. E. Schmitt et al., "Low-density lipoprotein stimulated peroxide production and endocytosis in cultured human endothelial cells: mechanisms of action," Endothelium-Journal of Endothelial Cell Research, vol. 5, no. 3, pp. 191-207, 2009.

[18] R. D. Manning, S. Meng, and N. Tian, "Renal and vascular oxidative stress and salt-sensitivity of arterial pressure," Acta Physiologica Scandinavica, vol. 179, no. 3, pp. 243-250, 2003.

[19] E. Ritz, "Total cardiovascular risk management," American Journal of Cardiology, vol. 100, no. 3, pp. S53-S60, 2007.

[20] E. Ritz, R. E. Schmieder, and C. A. Pollock, "Renal protection in diabetes: lessons from ONTARGET," Cardiovascular Diabetology, vol. 9, no. 1, p. 60, 2010.

[21] K. Lee, B. Kim, H. Hur, K. S. Chinannai, I. Ham, and H. Y. Choi, "Experimental research of hypotensive and hypolipidemic effects with modified Sanhuang Xiexin decoction," Chinese Journal of Integrative Medicine, pp. 1-7, 2017.

[22] O. Neamsuvan, P. Komonhiran, and K. Boonming, "Medicinal plants used for hypertension treatment by folk healers in Songkhla province, Thailand," Journal of Ethnopharmacology, vol. 214, pp. 58-70, 2018. 
[23] P. Russo, A. Frustaci, A. Del Bufalo, M. Fini, and A. Cesario, "Multitarget drugs of plants origin acting on Alzheimer's disease," Current Medicinal Chemistry, vol. 20, no. 13, pp. 16861693, 2013.

[24] T. Shen, G. Xing, J. Zhu et al., "Effects of 12-week supplementation of marine Omega-3 PUFA-based formulation Omega3Q10 in older adults with prehypertension and/or elevated blood cholesterol," Lipids in Health and Disease, vol. 16, no. 1, article no. 253, 2017.

[25] J. J. Ryan, D. A. Hanes, J. Corroon, J. Taylor, and R. Bradley, "Prospective safety evaluation of a cardiovascular health dietary supplement in adults with prehypertension and stage I hypertension," The Journal of Alternative and Complementary Medicine, vol. 25, no. 2, pp. 249-256, 2019.

[26] W. Liu, L. Wang, J. Yu, P. F. Asare, and Y. Q. Zhao, "Gastrodin reduces blood pressure by intervening with RAAS and PPAR $\gamma$ in SHRs," Evidence-Based Complementary and Alternative Medicine, vol. 2015, Article ID 828427, 8 pages, 2015.

[27] Mi. C. Kho, Y. J. Lee, J. D. Cha, K. M. Choi, D. G. Kang, and H. S. Lee, "Gastrodia elata ameliorates high-fructose diet-induced lipid metabolism and endothelial dysfunction," Evidence-Based Complementary and Alternative Medicine, vol. 2014, Article ID 101624, 2014.

[28] N. Bagherani, "Efficacy of topical spironolactone in treatment of acne," Dermatologic Therapy, vol. 28, no. 3, pp. 176-176, 2015.

[29] V. S. Gasilin, V. A. Kruglov, V. I. Titov, and T. I. Ushakova, "Moderate arterial hypertension during its natural course and in drug correction," Terapevticheskii arkhiv, vol. 61, pp. 15-17, 1989.

[30] Q.-H. Shao, X.-L. Zhang, Y. Chen et al., "Anti-neuroinflammatory effects of $20 \mathrm{C}$ from Gastrodia elata via regulating autophagy in LPS-activated BV-2 cells through MAPKs and TLR4/Akt/mTOR signaling pathways," Molecular Immunology, vol. 99, pp. 115-123, 2018.

[31] Z.-K. Liu, C.-F. Ng, H.-T. Shiu et al., "A traditional Chinese formula composed of Chuanxiong Rhizoma and Gastrodiae Rhizoma (Da Chuanxiong Formula) suppresses inflammatory response in LPS -induced RAW 264.7 cells through inhibition of NF- $\kappa$ B pathway," Journal of Ethnopharmacology, vol. 196, pp. 20-28, 2017.

[32] E.-K. Ahn, H.-J. Jeon, E.-J. Lim, H.-J. Jung, and E.-H. Park, "Anti-inflammatory and anti-angiogenic activities of Gastrodia elata Blume," Journal of Ethnopharmacology, vol. 110, no. 3, pp. 476-482, 2007.

[33] J. Zhu, R. Shi, S. Chen et al., "The relieving effects of brainpower advanced, a dietary supplement, in older adults with subjective memory complaints: a randomized, double-blind, placebo-controlled trial," Evidence-Based Complementary and Alternative Medicine, vol. 2016, Article ID 7898093, 16 pages, 2016.

[34] Y. Cai, G. Xing, T. Shen, S. Zhang, J. Rao, and R. Shi, "Effects of 12-week supplementation of Citrus bergamia extracts-based formulation CitriCholess on cholesterol and body weight in older adults with dyslipidemia: A randomized, double-blind, placebo-controlled trial," Lipids in Health and Disease, vol. 16, no. 1, 2017.

[35] Y. Fan, Y. Fei, L. Zheng et al., "Expression of endothelial cell injury marker Cd146 correlates with disease severity and predicts the renal outcomes in patients with diabetic nephropathy," Cellular Physiology and Biochemistry, vol. 48, no. 1, pp. 63-74, 2018.

[36] Z. Bi, X. Liang, A. Xu et al., "Hypertension prevalence, awareness, treatment, and control and sodium intake in shandong province, China: Baseline results from shandong-ministry of health action on salt reduction and hypertension (SMASH), 2011," Preventing Chronic Disease, vol. 11, no. 5, 2014.

[37] M. H. Badakhsh, M. Malek, R. Aghili, A. Ebrahim Valojerdi, and M. E. Khamseh, "Prehypertension; patient awareness and associated cardiovascular risk factors in an urban population in Iran," Medical Journal of The Islamic Republic of Iran, vol. 29, no. 1, pp. 1124-1128, 2015.

[38] M. Bozorgmanesh, H. Ghoreishian, R. Mohebi, F. Azizi, and F. Hadaegh, "Sex-specific predictors of the prehypertension-tohypertension progression: community-based cohort of a WestAsian population," European Journal of Preventive Cardiology, vol. 21, no. 8, pp. 956-963, 2013.

[39] A. I. Qureshi, M. F. K. Suri, J. F. Kirmani, and A. A. Divani, "Prevalence and trends of prehypertension and hypertension in united states: national health and nutrition examination surveys 1976 to 2000," Medical Science Monitor, vol. 11, no. 9, pp. 403409, 2005.

[40] A. I. Qureshi, M. F. K. Suri, J. F. Kirmani, A. A. Divani, and Y. Mohammad, "Is prehypertension a risk factor for cardiovascular diseases?” Stroke, vol. 36, no. 9, pp. 1859-1863, 2005.

[41] F. Assadi, "Prehypertension: a warning sign of future cardiovascular risk," International Journal of Preventive Medicine, vol. 5, pp. 4-9, 2014.

[42] B. M. Egan and S. Stevens-Fabry, "The importance of masked hypertension in adults with prehypertension," Nature Reviews Cardiology, vol. 12, no. 8, pp. 497-497, 2015.

[43] B. M. Egan and S. Stevens-Fabry, "Prehypertension-prevalence, health risks, and management strategies," Nature Reviews Cardiology, vol. 12, no. 5, pp. 289-300, 2015.

[44] I. J. Marshall, C. D. A. Wolfe, and C. McKevitt, "Lay perspectives on hypertension and drug adherence: Systematic review of qualitative research," BMJ, vol. 345, no. 7867, Article ID e3953, 2012.

[45] W. Cheng, J. Li, T. You, and C. Hu, "Anti-inflammatory and immunomodulatory activities of the extracts from the inflorescence of Chrysanthemum indicum Linné," Journal of Ethnopharmacology, vol. 101, no. 1-3, pp. 334-337, 2005.

[46] Z. Shunying, Y. Yang, Y. Huaidong, Y. Yue, and Z. Guolin, "Chemical composition and antimicrobial activity of the essential oils of Chrysanthemum indicum," Journal of Ethnopharmacology, vol. 96, pp. 151-158, 2005.

[47] T. Kato, K. Noguchi, M. Sakanashi et al., "Effects of the water extract of Chrysanthemum indicum Linn. on coronary and systemic hemodynamics in the dog," Archives Internationales de Pharmacodynamie et de Thérapie, vol. 280, no. 2, pp. 241-253, 1986.

[48] T. Kato, K. Noguchi, Y. Miyamoto et al., "Effects of Chrysanthemum indicum Linn. on coronary, vertebral, renal and aortic blood flows of the anesthetized dog," Archives Internationales de Pharmacodynamie et de Thérapie, vol. 285, no. 2, pp. 288-300, 1987.

[49] M. S. Cheon, T. Yoon, D. Y. Lee et al., "Chrysanthemum indicum Linné extract inhibits the inflammatory response by suppressing NF- $\kappa$ B and MAPKs activation in lipopolysaccharideinduced RAW 264.7 macrophages," Journal of Ethnopharmacology, vol. 122, no. 3, pp. 473-477, 2009.

[50] K. Yoo, I. Kim, J. Cho et al., "Neuroprotection of Chrysanthemum indicum Linne against cerebral ischemia/reperfusion injury by anti-inflammatory effect in gerbils," Neural Regeneration Research, vol. 11, no. 2, p. 270, 2016. 
[51] D.-W. Kim, T. Yokozawa, M. Hattori, S. Kadota, and T. Namba, "Inhibitory effects of an aqueous extract of Apocynum venetum leaves and its constituents on $\mathrm{Cu} 2+$-induced oxidative modification of low density lipoprotein," Phytotherapy Research, vol. 14, no. 7, pp. 501-504, 2000.

[52] D. Kim, T. Yokozawa, M. Hattori, S. Kadota, and T. Namba, "Effects of aqueous extracts of Apocynum venetum leaves on spontaneously hypertensive, renal hypertensive and $\mathrm{NaCl}$-fedhypertensive rats," Journal of Ethnopharmacology, vol. 72, no. 12, pp. 53-59, 2000.

[53] K. Asaba, A. Tojo, M. L. Onozato et al., "Effects of NADPH oxidase inhibitor in diabetic nephropathy," Kidney International, vol. 67, no. 5, pp. 1890-1898, 2005.

[54] T. S. Lapperre, L. A. Jimenez, F. Antonicelli et al., "Apocynin increases glutathione synthesis and activates AP-1 in alveolar epithelial cells," FEBS Letters, vol. 443, no. 2, pp. 235-239, 1999.

[55] D. B. Pearse and J. M. Dodd-o, "Ischemia-reperfusion lung injury is prevented by apocynin, a novel inhibitor of leukocyte NADPH oxidase," Chest, vol. 116, pp. 55S-56S, 1999.

[56] R. A. Beswick, A. M. Dorrance, R. Leite, and R. C. Webb, "NADH/NADPH oxidase and enhanced superoxide production in the mineralocorticoid hypertensive rat," Hypertension, vol. 38, no. 5, pp. 1107-1111, 2001.

[57] T. Yokozawa and T. Nakagawa, "Inhibitory effects of Luobuma tea and its components against glucose-mediated protein damage," Food and Chemical Toxicology, vol. 42, no. 6, pp. 975-981, 2004.

[58] G. Fan, Z. Wang, L. Zhang et al., "Prevalence, awareness, treatment and control of hypertension in rural areas in North China in 2013," Zhonghua Yi Xue Za Zhi, vol. 95, pp. 616-620, 2015.

[59] Q. Zhang, J. J. Zhao, J. Xu, F. Feng, and W. Qu, "Medicinal uses, phytochemistry and pharmacology of the genus Uncaria," Journal of Ethnopharmacology, vol. 173, pp. 48-80, 2015.

[60] Y. He, H. Yang, Q. Yang et al., "Yiqi Huaju formula, a Chinese herbal medicine, reduces arterial pressure in saltsensitive hypertension by inhibiting renin-angiotensin system activation," Molecular Medicine Reports, vol. 12, no. 4, pp. 53215327, 2015.

[61] L. Cai, A. Liu, L. Zhang, S. Li, and P. Wang, "Prevalence, awareness, treatment, and control of hypertension among adults in Beijing, China," Clinical and Experimental Hypertension, vol. 34, no. 1, pp. 45-52, 2012.

[62] X. Chen, L. Li, T. Zhou, Z. Li, and R. Clarke, "Prevalence of hypertension in rural areas of China: a meta-analysis of published studies," PLoS ONE, vol. 9, no. 12, Article ID e115462, 2014.

[63] A. A. M. Adly, N. S. Elbarbary, E. A. R. Ismail, and S. R. Hassan, "Plasminogen activator inhibitor-1 (PAI-1) in children and adolescents with type 1 diabetes mellitus: relation to diabetic microvascular complications and carotid intima media thickness," Journal of Diabetes and its Complications, vol. 28, no. 3, pp. 340347, 2014.

[64] A. A. Abdellatif, "Role of single-pill combination therapy in optimizing blood pressure control in high-risk hypertension patients and management of treatment-related adverse events," The Journal of Clinical Hypertension, vol. 14, no. 10, pp. 718-726, 2012.

[65] L. Ahmad, A. Semotiuk, M. Zafar et al., "Ethnopharmacological documentation of medicinal plants used for hypertension among the local communities of DIR Lower, Pakistan," Journal of Ethnopharmacology, vol. 175, pp. 138-146, 2015.
[66] M. Chen, J. Wu, Q. Luo et al., “The anticancer properties of Herba Epimedii and its main bioactive componentsicariin and icariside II," Nutrients, vol. 8, no. 9, 2016.

[67] C. Rüster and G. Wolf, "Angiotensin II as a morphogenic cytokine stimulating renal fibrogenesis," Journal of the American Society of Nephrology, vol. 22, no. 7, pp. 1189-1199, 2011.

[68] X. Zhang, Z. Ao, A. Bello et al., "Characterization of the inhibitory effect of an extract of Prunella vulgaris on Ebola virus glycoprotein (GP)-mediated virus entry and infection," Antiviral Research, vol. 127, pp. 20-31, 2016.

[69] Y. Hu, C. Yu, F. Wu et al., "Antihepatofibrotic effects of aqueous extract of prunella vulgaris on carbon tetrachloride-induced hepatic fibrosis in rats," Planta Medica, vol. 82, pp. 97-105, 2016.

[70] H. Fazal, B. H. Abbasi, N. Ahmad, S. S. Ali, F. Akbar, and F. Kanwal, "Correlation of different spectral lights with biomass accumulation and production of antioxidant secondary metabolites in callus cultures of medicinally important Prunella vulgaris L.," Journal of Photochemistry and Photobiology B: Biology, vol. 159, pp. 1-7, 2016.

[71] H. G. Choi, T. H. Kim, S. Kim, and J. A. Kim, "Anti-allergic inflammatory triterpenoids isolated from the spikes of Prunella Vulgaris," Natural Product Communications (NPC), vol. 11, no. 1, pp. 31-32, 2016.

[72] H. Toyoshima, K. Takahashi, and T. Akera, "The impact of side effects on hypertension management: a japanese survey," Clinical Therapeutics, vol. 19, no. 6, pp. 1458-1469, 1997.

[73] R. J. Chen, T. Chung, F. Li, W. Yang, T. Jinn, and J. T. Tzen, "Steroid-like compounds in Chinese medicines promote blood circulation via inhibition of Na+/K+-ATPase," Acta Pharmacologica Sinica, vol. 31, no. 6, pp. 696-702, 2010.

[74] M.-S. Chern, F.-C. Lin, and D. Wu, "Comparison of clinical efficacy and adverse effects between extended- release felodipine and atenolol in patients with mild and moderate essential hypertension," Chang Gung Medical Journal, vol. 20, no. 2, pp. 86-93, 1997.

[75] J. Wang, Q. Huang, and Y. Li, "Overview of clinical use and side effect profile of valsartan in Chinese hypertensive patients," Drug Design, Development and Therapy, vol. 8, pp. 79-86, 2013.

[76] R. L. Coleman, M. F. Brady, T. J. Herzog et al., "Bevacizumab and paclitaxel-carboplatin chemotherapy and secondary cytoreduction in recurrent, platinum-sensitive ovarian cancer (NRG Oncology/Gynecologic Oncology Group study GOG-0213): a multicentre, open-label, randomised, phase 3 trial," The Lancet Oncology, vol. 18, no. 6, pp. 779-791, 2017.

[77] X. Yang, Q. Wang, Z. Pang, M. Pan, and W. Zhang, “Flavonoidenriched extract from Hippophae rhamnoides seed reduces high fat diet induced obesity, hypertriglyceridemia, and hepatic triglyceride accumulation in C57BL/6 mice ", Pharmaceutical Biology, vol. 55, no. 1, pp. 1207-1214, 2016.

[78] K. Shu, M. Wu, C. Chen, C. Cheng, J. Lian, and Y. Lu, "Effect of pentoxifylline on graft function of renal transplant recipients complicated with chronic allograft nephropathy," Clinical Nephrology, vol. 67, no. 03, pp. 157-163, 2007.

[79] M. H. Chen, T. L. Pan, J. W. Hsu et al., "Risk of type 2 diabetes in adolescents and young adults with attentiondeficit/hyperactivity disorder: a nationwide longitudinal study," Journal of Clinical Psychiatry, vol. 79, no. 3, 2018.

[80] A. de la Sierra, "Mitigation of calcium channel blockerrelated oedema in hypertension by antagonists of the renin-angiotensin system," Journal of Human Hypertension, vol. 23, no. 8, pp. 503-511, 2009. 
[81] S. Sagi, B. Avula, Y. Wang, and I. A. Khan, "Quantification and characterization of alkaloids from roots of Rauwolfia serpentina using ultra-high performance liquid chromatography-photo diode array-mass spectrometry," Analytical and Bioanalytical Chemistry, vol. 408, no. 1, pp. 177-190, 2016.

[82] S. D. Shamon and M. I. Perez, "Blood pressure-lowering efficacy of reserpine for primary hypertension," Cochrane Database of Systematic Reviews, vol. 12, Article ID CD007655, 2016.

[83] S. D. Shamon and M. I. Perez, "Blood pressure lowering efficacy of reserpine for primary hypertension," Cochrane Database of Systematic Reviews, Article ID CD007655, 2009.

[84] D. Lobay, "Rauwolfia in the treatment of hypertension," Integrative Medicine (Encinitas), vol. 14, pp. 40-46, 2015.

[85] D. Zhu, P. Gao, W. Holtbruegge, and C. Huang, "A randomized, double-blind study to evaluate the efficacy and safety of a singlepill combination of telmisartan $80 \mathrm{mg} /$ amlodipine $5 \mathrm{mg}$ versus amlodipine $5 \mathrm{mg}$ in hypertensive Asian patients," Journal of International Medical Research, vol. 42, no. 1, pp. 52-66, 2014.

[86] S. LogaZec, M. Asceric, N. LogaAndrijic, B. Kapetanovic, and E. Zerem, "The incidence of antihypertensive drug-induced side effects in patients with diabetes mellitus type 2 and hypertension," Medical Archives, vol. 68, no. 6, pp. 372-375, 2014.

[87] N. Kloth and A. S. Lane, "ACE inhibitor-induced angioedema: a case report and review of current management," Critical Care \& Resuscitation Journal, vol. 13, pp. 33-37, 2011.

[88] J. M. Cruickshank, "Beta-blockers and heart failure," Indian Heart Journal, vol. 62, no. 2, pp. 101-110, 2010.

[89] G. Iaccarino, V. Trimarco, F. Lanni et al., " $\beta$-Blockade and increased dyslipidemia in patients bearing Glu27 variant of $\beta 2$ adrenergic receptor gene," The Pharmacogenomics Journal, vol. 5, no. 5, pp. 292-297, 2005.

[90] R. Ames, "Hyperlipidemia of diuretic therapy," Archives des Maladies du Cour et des Vaisseaux, vol. 91, pp. 23-27, 1998.

[91] T. Shen, J. Wang, Y. Yu, and J. Yu, "Comparison of realworld effectiveness between valsartan and non-RAS inhibitor monotherapy on the incidence of new diabetes in Chinese hypertensive patients: An electronic health recording system based study," Clinical and Experimental Hypertension, vol. 41, pp. 244-254, 2019.

[92] L. M. Souza, R. Riera, H. Saconato, A. Demathé, and Á. N. Atallah, "Oral drugs for hypertensive urgencies: systematic review and meta-analysis," São Paulo Medical Journal, vol. 127, no. 6, pp. 366-372, 2009. 


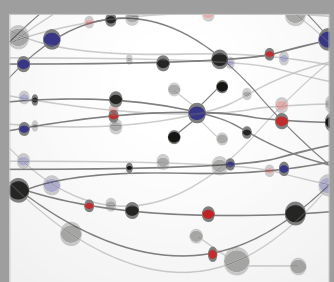

The Scientific World Journal
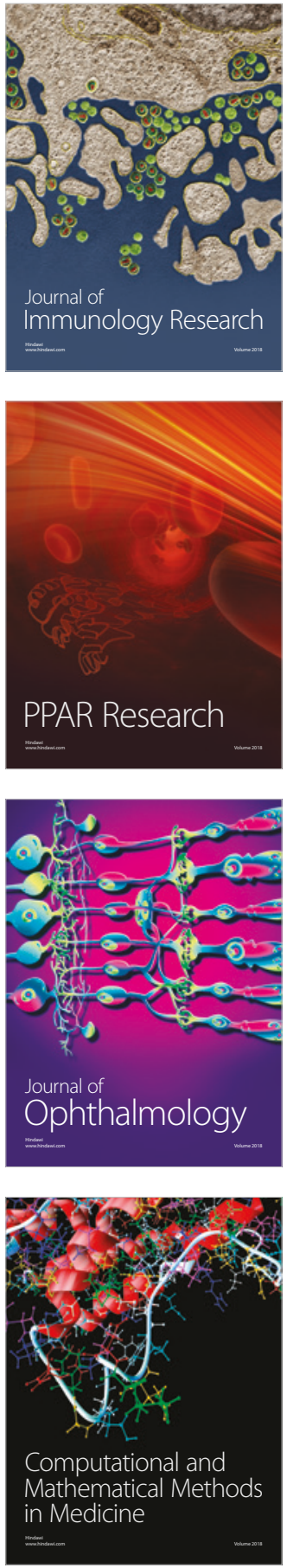

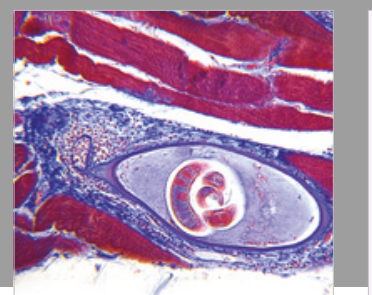

Gastroenterology Research and Practice

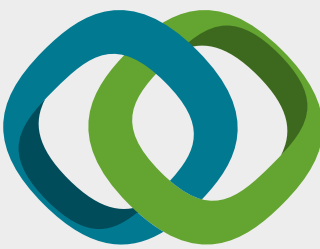

\section{Hindawi}

Submit your manuscripts at

www.hindawi.com
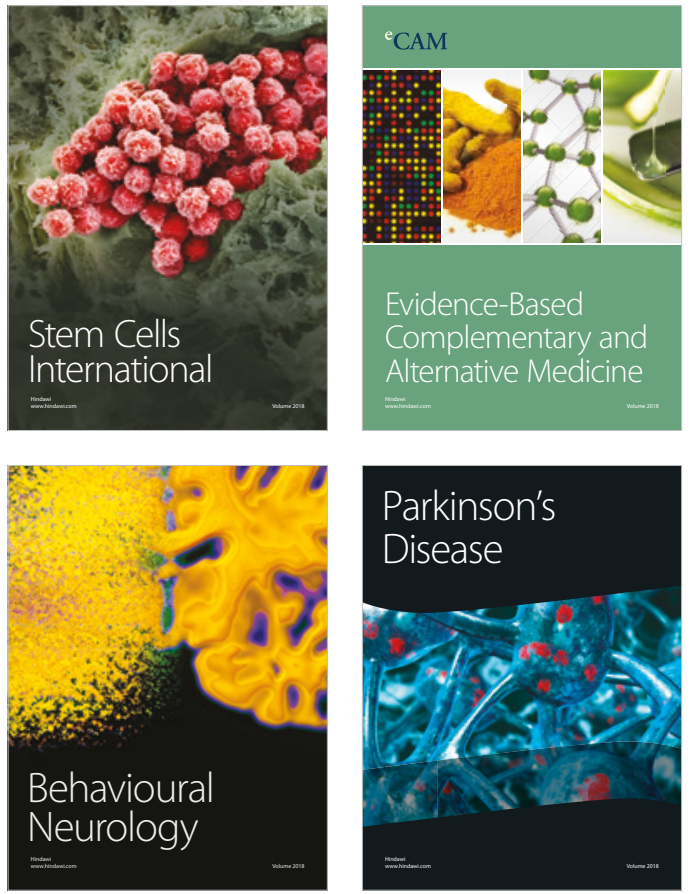

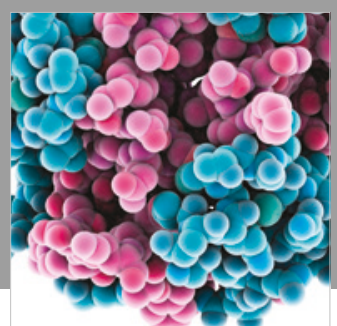

ournal of

Diabetes Research

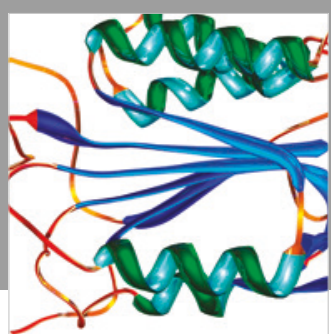

Disease Markers
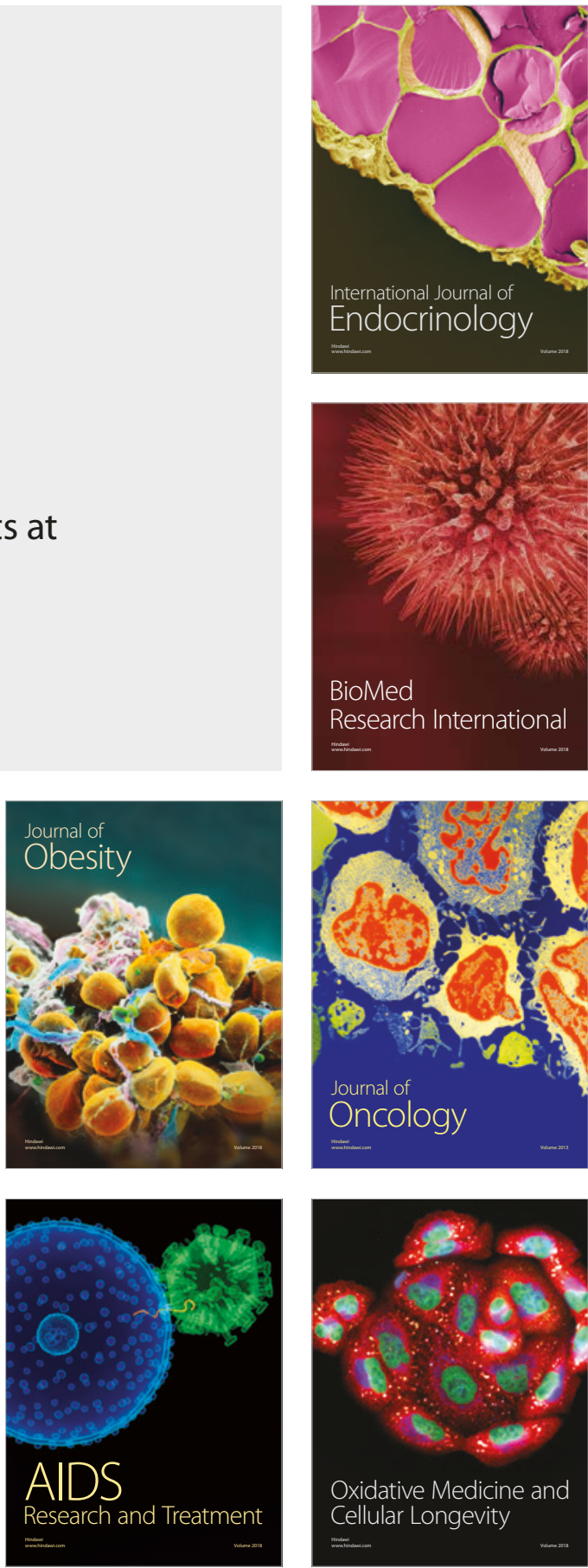